\title{
Grief-focused psychological intervention in exploration and alteration of the emotional reaction in a child: a case study
}

\author{
Susmita Halder ${ }^{1}$, Shinjini Samajdar ${ }^{2}$ \\ ${ }^{1}$ Associate Professor, AIBHAS, Amity University, Kolkata. \\ ${ }^{2}$ M.Phil Clinical Psychology Trainee, AIBHAS, Amity University, Kolkata. \\ Corresponding author: Susmita Halder \\ Email-shalder@kol.amity.edu
}

\begin{abstract}
Grief is an inevitable, never-ending process that results from a permanent or temporary disruption in a routine, a separation, or a change in a relationship that may be beyond the person's control. These changes cause pain and discomfort and impact the person's thoughts, feelings, and behaviors. The feelings of grief and loss experiences in children could be manifested emotionally and behaviorally in a more challenging way. Regardless of type of grief/loss, the feeling of emptiness, anger, confusion, desperation and insecurity are prominent features in children. Grief reactions manifest maladaptive behaviors, such as, anger outburst, irritability, loss of appetite and sleep. The present study is aimed to resolve grief reaction of a 10 years old male child, student, and hailing from urban area. Intervention plan was focused to explore, alter and resolve the grief reactions through grief focused psychotherapy in collaboration with supportive psychotherapy techniques. It has been seen that, exploration of feelings of grief, emotional catharsis techniques, reassurance, externalization of interest, relationship analysis, enhancement of self esteem, preserving memories, acceptance of loss and guidance for future engagements decreased the grief reaction in the child. So, it can be concluded that, though there are challenges in directing and evaluating grief reactions in children, collective approaches could be effective.
\end{abstract}

Keywords: grief, emotional reaction, child, psychological intervention, psychotherapy.

(Paper received $-5^{\text {th }}$ August 2020, Peer review completed $-10^{\text {th }}$ August 2020)

(Accepted $-18^{\text {th }}$ August 2020)

\section{INTRODUCTION}

Grief is defined as an emotion associated with sadness with loss or bereavement which leads to deep and intense psychological distress or suffering. Bereavement includes mourning and grief, which is the ritualized expression of loss. One such grief is complicated grief which comprises of chronic and delayed grief and is exaggerated in nature. Complicated grief is related with a significant loss and trauma including violent and unexpected deaths; multiple loses, and may be exacerbated by unresolved grief, chronic stress and distress, mental illness and lack support systems. Reactions to grief by adults and children are quite different, and it is at times very complex in respect to children. After a significant loss, children behave differently; older children or young adolescents often will feel helpless and frightened, some may want to retreat to childhood, where they had a sense of protection from death or loss, but they often feel a compulsion by social expectation to act more like an adult. Therefore, they may suppress their emotions. Grief related psychotherapeutic techniques target the feelings of loss and bereavement and to adapt with the changed environment with the acceptance of reality. Grief counselling techniques and supportive psychotherapy are the evidenced based therapy which has explored and minimised the grief in children. [1]. Before intervention with children, the involvement of parents and other caretakers in the psychotherapeutic process is necessary to deal with the present grief or bereavement [2]. Four tasks that children work through as they mourn a loss which include understanding, grieving, commemorating, and 
moving on [3]. The task of grieving means allowing children or adolescents to explore and experience the painful emotions linked with a loss [4]. In accordance to evidenced base therapeutic techniques those are previously established for children with grief and loss the application and the improvement might not provide positive outcome for each child due to the underlying individual factors. In the present case study, application of eclectic approach which includes primarily grief -focused psychotherapy, along with supportive psychotherapy and to see its efficacy in child's behavior was comprehended.

\section{CASE REPORT}

\section{Details of the Case}

The index client, 10 years old, male, student, hailing from urban area of Kolkata, India, presented with the complaints of low mood, crying spells and poor sleep, precipitated with father's death. Informant also reported, child showed irritability, and night terrors, at times. Interview revealed presence of self-blame, feeling helplessness and hopelessness along with poor concentration in studies developed recently. The psycho therapeutic intervention was conducted in an urban clinic in Kolkata, India, continued for two months, with total number of 8 sessions, duration per session was 45- 50 minutes.

\section{Psychotherapeutic Formulation for Intervention}

In psychotherapy plan, the main target was to deal with the symptoms of grief and grief focused psychological intervention, along with techniques of supportive psychotherapy were also used for channelizing his loss or grief feelings. Grief-focused psychotherapy was focused on talking about death, mourning the loss, addressing ambivalent feelings, preserving positive memories, redefining the relationship, committing to other relationships, and meaning-making out of the loss. The overall relationship analysis and re-defining the meaning of death and loss was analysed. Supportive therapy helped child to release hispent-up emotions due associated with loss and grief. The client's future planning and motivation to lead a proper life was also included in therapy process.

\section{Table: 1 Grief-focused Psychotherapy plan}

\begin{tabular}{|l|l|}
\hline Target Behavior & Intervention Techniques \\
\hline $\begin{array}{l}\text { Redefining and improving insight regarding } \\
\text { condition }\end{array}$ & Psychoeducation \\
\hline $\begin{array}{l}\text { Catharsis of pent up emotions } \\
\text { Improving expressions of emotions }\end{array}$ Arrangement of daily activities & $\begin{array}{l}\text { Supportive Psychotherapy- } \\
\text { Emotional Catharsis } \\
\text { Reassurance } \\
\text { Externalization of interests }\end{array}$ \\
\hline $\begin{array}{l}\text { Evaluation and analysis of relationship with } \\
\text { father }\end{array}$ & $\begin{array}{l}\text { Grief-focused Psychotherapy- } \\
\text { Improvement of self-perception } \\
\text { Reducing self blaming }\end{array}$ \\
$\begin{array}{l}\text { Improvement of level of acceptance } \\
\text { Planning for future }\end{array}$ & $\begin{array}{l}\text { Self perception evaluation } \\
\text { Preservation of positive memories and acceptance of } \\
\text { loss } \\
\text { Guidance and planning for future engagements }\end{array}$ \\
\hline
\end{tabular}

\section{Psychotherapy Process \\ Psychoeducation}

Psychotherapy session begins with proper psycho-education, where the ethics of confidentiality was explained to the child and he was assured to share his feelings in terms of the loss he recently faced. The child was not comfortable in the initial session to discuss about his loss, gradually he started sharing but crying spells were present during conversation. The insight regarding the process of death, causes of death and the concept of inevitable nature of death were explained and discussed with the child, in simple languages. The child was provided with some metaphors and stories and figures were drawn in the process 
of explaining. In alternative sessions, he was asked about different questions and a discussion about the inevitable nature of death was conducted. The insight was enhanced through the sessions.

\section{Emotional Catharsis}

Catharsis of repressed feelings due to the death of his father were initiated through discussing about the cause of death of his father and the associated obvious emotion related to this condition. Through drawing and story making related to the death of his father, emotional catharsis session was conducted. In few sessions, crying spells and weeping were significantly decreased in the child.

\section{Reassurance}

It was observed that the child used to feel distressed, feeling hopeless regarding future without his father, and could not able to control his feelings of loss. In the session, he was reassured and motivated through supportive therapy which helped him to get comfort using his own resources.

\section{Externalization of Interest and Activity Scheduling}

Further, to improve his level of engagement and for increase emotional expressions, the child's hobbies and interest areas were explored and daily activities were planned accordingly. Activities included art and craft and story making in certain topics which included in activity schedule also helped him to express his emotion in better way. Through these activities, it came out that he saw his father in dreams in every alternative day, which caused distress and night terrors reported by care giver. The client was asked to discuss about his dreams in sessions and related emotions.

\section{Relationship Analysis}

The grief focused intervention includes analysis of relationship with the lost ones. The analysis included exploration of feelings related to the loss, the communication pattern with the father, impact of loss in child's daily life, changes in behavior due to loss, dreams regarding the lost ones which was already explored, the impact of relationship of the child with other family members, impact of loss in other members of the family and finally, financial condition of the family. It was explored that, the communication pattern of the child with his father was cordial, but relationship between his parents was non-congenial. The child's father was the earning member of the family, the loss implied financial burden as well. Gradually through multiple sessions, understanding of relationship with the lost ones, helped the child to evaluate the feelings and worth of his feelings, which leaded to release pent up emotions as well.

\section{Evaluation of Self-perception}

In the next phase, it was explored that, child's perception about himself was mainly negative, he used to think he is responsible for the death of his father, and to feel sad, irritable, and loosing concentration in studies. The child asked about his positive and negative qualities and asked him to rate in accordance with the qualities and consequences of those behaviors/qualities. Alternative behavioral patterns were also asked for the negative ones. Enhancement of self esteem through different examples in this context was also done.

\section{Preservation of Positive Memories and Acceptance of Loss}

Preservation of positive memories is one of the most important techniques to intervene grief and bereavement. In the process of exploration, multiple good memories of the child with his father in different situations were found and the related feelings and emotions were discussed. The client was asked to express his feelings by drawing those situations as much he can, and the need to preserve those memories was discussed with child. The inevitable nature of the death was already discussed with the child and through preserving good memories and using own resources to accept the loss and expressing his feelings in the process of acceptance was also discussed through sessions.

\section{Guidance and Planning for Future Academics}

In later sessions, as psychotherapy process progressed, it was seen the feelings of grief was decreased, and the child was engaged more in academic activities and other daily chores. His behavioral symptoms in accordance with grief feelings were also decreased than before as reported by the care giver and child as well. A comprehensive guidance through planning of future academics and engagements along with his interest areas were discussed with the child.

\section{Outcome of the Therapy}


Therapeutic intervention was conducted over 8 sessions and after regular session significant improvement was found in the child's behavior and emotion. The child engaged in daily life routines and his overall functioning, including academic involvement also enhanced than before. (Figure I)

\section{DISCUSSION}

The case report presented above showed that, the efficacy of grief- focused psychotherapy, along with supportive techniques in the child with symptoms of grief and bereavement. Childhood disorders like $\mathrm{ADHD}$, conduct problems, affective disorders and obsessive-compulsive disorders in children can be

Table 2: Improvement in Pre and Post Intervention

\begin{tabular}{|c|c|c|}
\hline Measures & Pre-Intervention & Post-Intervention \\
\hline \multicolumn{3}{|c|}{ Quantitative Measure } \\
\hline Child Depression Inventory (CDI) & $\begin{array}{c}19 \text { (Very much above } \\
\text { average) }\end{array}$ & 05 (Average) \\
\hline Clinical features/ symptoms \\
\hline Crying spells & Present & Absent \\
\hline Night terrors & Present & Absent \\
\hline Expressing Emotions & Qualitative Measures \\
\hline Level of acceptance & Complete denial & Acceptance of the reality \\
\hline Self-Blame & Present & Absent \\
\hline Social Interaction & Poor & Improved \\
\hline
\end{tabular}

Figure 1: Grief -focused psychotherapy in accordance to Kubler Ross grief model

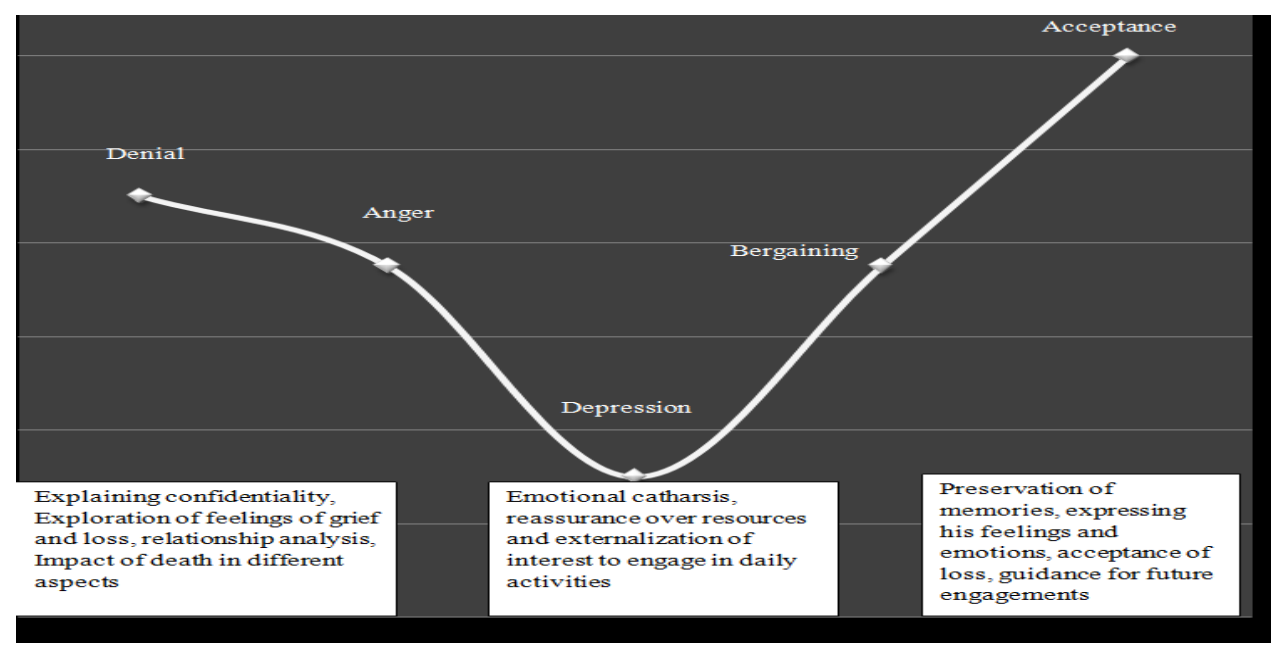

treated and found effective using different psychodynamic and Cognitive Behavioral approaches [5-7]. The children with trauma or grief could be treated through different psychotherapeutic approaches, namely, psychodynamic approach, existential approach and cognitive behavioral approaches, but the effectiveness is depending on the individual him/herself. [8-10].

The current case report indicated that, the clinical features which were present in the child due to grief reactions such as, low mood, crying spells and night terrors are decreased and resolved through grief focused psychotherapy. Many evidenced based therapeutic interventions related to grief reactions is indicated to the child or adolescent who exposed to traumatic life events, namely, death of near ones which leads to functional impairment [11-13]. The grief focused psychotherapy was also improved the 
expressions of emotions along with acceptance of reality and decreased the self-blaming than before [12]. Educating and reassuring the person suffering from grief reactions and improvement of interactional pattern with others can help to move forward and significant changes in major decision making and judgment improve coping in long term as well [13].

Grief-focused psychotherapeutic intervention facilitates the understanding of the inevitable nature of death, and its consequences in different aspects of the daily life. Grief focused intervention helped the child's growth and progress by conserving positive memories and acceptance of the reality, finally the guidance for future planning in terms academics and other engagements. Supportive psychotherapy is effective in reducing different behavioral symptoms in children with conduct disorders, anxiety disorders, eating disorders and obsessive compulsive disorders [14-16]. Grief and trauma focused psychotherapeutic intervention reduces the child's grief reactions and helps him in resolving the feelings of loss and bereavement [17]. Present case report also focuses on the supportive psychotherapeutic techniques which includes emotional catharsis, reassurance and externalization of interest that impedes the low mood, crying spells, weeping and negative connotations of the situations.

\section{CONCLUSION}

The present case report was aimed to understand the efficacy of supportive and grief focused psychotherapeutic approach on a child with feelings of grief and loss. The emotional reactions associated with death of near ones and how grief reactions changed through different measures of intervention techniques were perspicuous. In the case of a child, understanding the meaning of death and releasing pent up emotions in relation to death were established. Also, through assuring own strength and the acceptance of reality helped the child to move towards the mainstream.

\section{REFERENCES}

1. Piper WE, McCallum M, Joyce AS, Rosie JS, Ogrodniczuk JS. Patient personality and time-limited group psychotherapy for complicated grief. Int J Group Psychother 2001;51(4):525-52.

2. Baggerly J, Abugideiri SE. Grief counseling for Muslim preschool and elementary school children. J Multicult Couns Dev 2010;38(2):112-24.

3. Fox SS. Good grief: Helping groups of children when a friend dies. New England Association for the Education of Young Children; 1985.

4. Trozzi M. Talking with children about loss: Words, strategies, and wisdom to help children cope with death, divorce, and other difficult times. New York: Penguin Putnam: 1999.

5. Picardi A, Gaetano P. Psychotherapy of mood disorders. Clin Pract Epidemiol Ment Health 2014;10:140-58.

6. Young C. The Transportability and Utility of Cognitive Therapy in South African Contexts: A Review. J Psychol Africa 2009;19(3):407-14.

7. Chakraborty S, Halder S. Adaptation of cognitive behaviour therapy in childhood obsessive-compulsive disorder: a case study. Open J Psychiatr Allied Sci 2020;11:48.

8. Delgado SV. Psychodynamic psychotherapy for children and adolescents: an old friend revisited. Psychiatry 2008;5(5):67-72.

9. Walters DA. Grief and loss: towards an existential phenomenology of child spirituality, Int J Childr Spirituality 2008;13(3):277-86.

10. Mariken S, Annemarie ,L, Paul, A. Cognitive-Behavioral Therapy for Prolonged Grief in Children: Feasibility and Multiple Baseline Study. Cogn Behav Pract 2013;20(3):349-61.

11. Saltzman WR, Pynoos RS, Layne CM, Steinberg AM, Aisenberg E. Trauma- and grief-focused intervention for adolescents exposed to community violence: Results of a school-based screening and group treatment protocol. Group Dynam Theory Res Pract 2001;5(4):291-303.

12. Paula LH. Treatment of bereavement-related depression and traumatic grief. J Affect Disord 2006;92(1):11724.

13. Allumbaugh DL, Hoyt WT. Effectiveness of grief therapy: A meta-analysis. J Couns Psychol 1999;46(3): 370-80.

14. Neimeyer RA, Burke LA, Mackay MM, van Dyke Stringer JG. Grief therapy and the reconstruction of meaning: From principles to practice. J Contempor Psychother 2010;40(2):73-83.

15. Clements PT, DeRanieri JT, Vigil GJ, Benasutti KM. Life After Death: Grief Therapy After the Sudden Traumatic Death of a Family Member. Perspect Psychiatr Care 2004;40(4):149-54.

16. Grange D, Crosby RD, Rathouz PJ, Leventhal BL. A Randomized Controlled Comparison of Family-Based Treatment and Supportive Psychotherapy for Adolescent Bulimia Nervosa. Arch Gen Psychiatry 2007;64(9):1049-56. 
17. Herbert JD, Gaudiano BA, Rheingold AA, Moitra E, Myers VH, Dalrymple KL, Brandsma LL. Cognitive behavior therapy for generalized social anxiety disorder in adolescents: A randomized controlled trial. J Anxiety Disord 2009;23(2):167-77.

18. Baker K. Conduct disorders in children and adolescents. Pediatr Child Health 2013;23(1):24-9.

19. Meredith E, Victoria E. Resolving Child and Adolescent Traumatic Grief: Creative Techniques and Interventions. J Creativity Ment Health 2010;5(2):158-76.

\section{Acknowledgements - Nil \\ Conflict of Interest - Nil \\ Funding - Nil}

